\section{Christmas quiz}

\section{Guess the advert}

One day I found myself gazing at a picture of a man leaping over a bed in a room decorated with wallpaper patterned with boiled eggs. To my amazement I discovered I was looking at an advertisement for an inhaler ... and so started this quiz, which can be played anywhere, anytime, in the privacy of your own home, on the train, or on the plane. It's called "Guess the advert." All you need is a handy copy of any medical publication which carries advertisements (ordinary commercial adverts are generally too transparent).

I undertook a straw poll among colleagues and friends on the subject of a number of recent adverts. The man leaping over the bed, mentioned above, was thought to be an advertistment for the National Lottery, the Egg Marketing Board, a bed manufacturer, and a breakfast cereal. Actually it was an advertisement for an inhaler. A woman with exotic dreadlocks was not representing Versace or Vivienne Westwood fashions - rather, a non-steroidal anti-inflammatory drug. A man leaping over a woman might, thought the sample, be advertising Viagra, or a stage show; in reality, it was advertising a statin.

Now try your hand at "guess the advert." Possibilities - and the actual answers-are given at the bottom of the page. After this, pharmaceutical advertisements will never be quite the same!
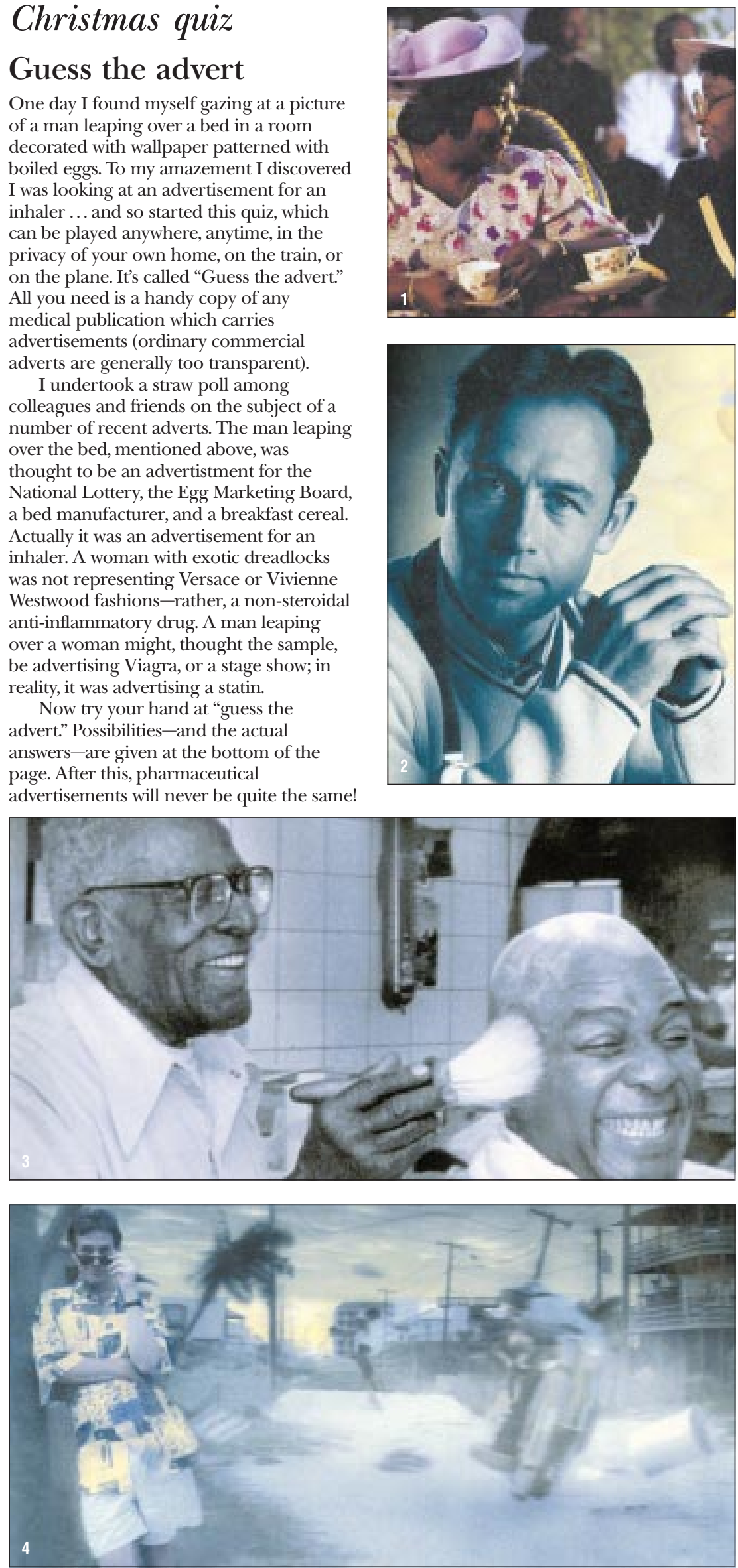
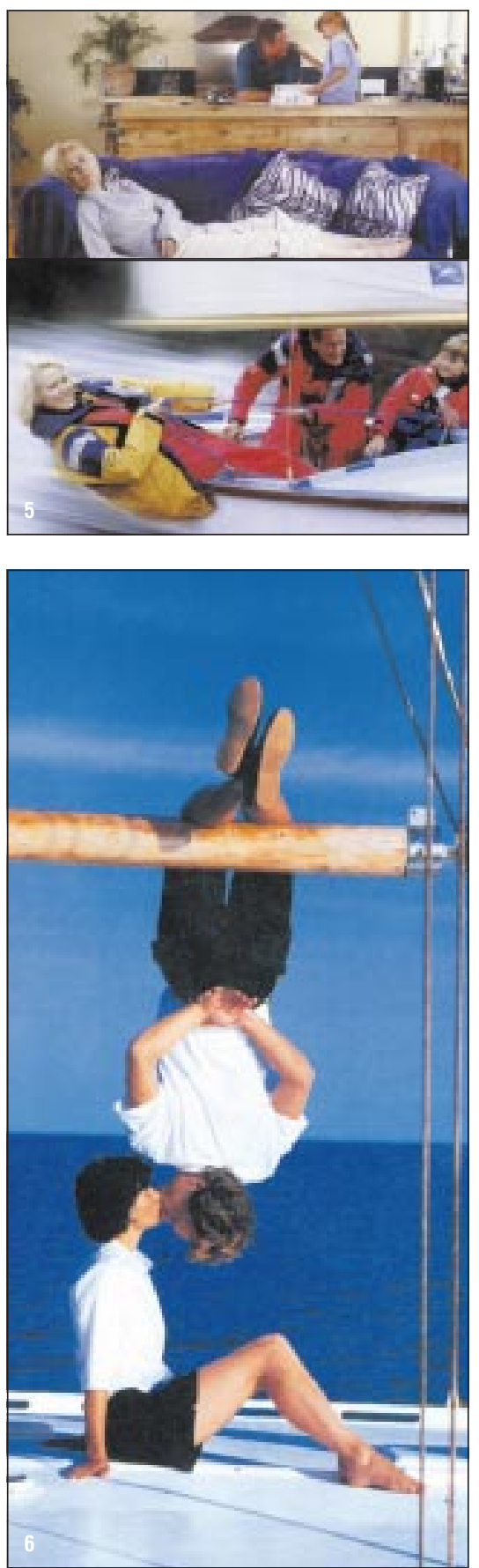

The quiz was drawn up by C M Tyrie, consultant psychiatrist, County Durham and Darlington Priority Services NHS Trust, Darlington DL3 6HX.

\section{Answers}

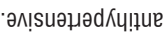

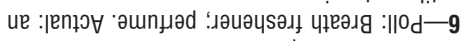

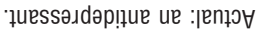

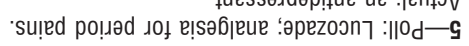

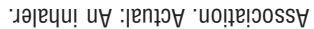
ә|!qouoln 'puessesdap!̣ue

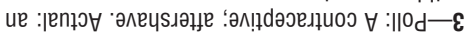

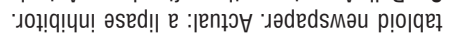

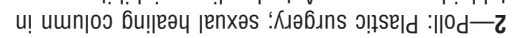

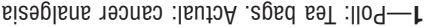

